\title{
Maqashid As-Ayari'ah sebagai Dasar Pengembangan Ekonomi Islam
}

\author{
Nasitotul Janah \\ Universitas Muhammadiyah Magelang \\ E-mail: Nasitotuljanah76@gmail.com
}

Abdul Ghofur

Universitas Islam Negeri Walisongo

E-mail: Aghofur2009@gmail.com

\begin{abstract}
In contrast to the secular economy of capitalism and socialism, Islamic Economy is the one built on syari'ah bases, norms and divine transcendent values in the divine revelation, the al-Qur'an and the hadis. In order to understand the essence of syari'ah, it is necessary to conduct shifting paradigm from a literalist approach merely focusing on textual and legal meaning to a substantialist approach seeking to capture the moral ideas and the original meaning of the syari'ah beyond the text, which are trans-historical or transcendental being and universal (general principle). This paradigm shifting occurs as the text is limited while the reality is infinite. Among the substantialist approaches offered is the use of maqashid syari'ah and mashlahah. Maqashid syari'ah refers to the essence of God's intention (Law Giver), which is the most essential formulated into five elements, they are: حفظ الدين (the religion keeping), حفظ النفس (the soul keeping), حفظ العقل (the intellect keeping), حفظ النسل (descendant keeping) and المال حفظ (the wealth keeping). Then, hierarchically, maqashid in classical theory is developed into 3 levels: الضرورية (primary needs/basic necessity), الحاجية (secondary needs), and التحسينة (tertiary needs). Under the argument of maqashid syari'ah, this Islamic economic concept must be developed, therefore on the one hand the Islamic economy will not lose its divine morality, but on the other hand it can also develop dynamically, progressively and even ready to handle the contemporary economic problems. Based on the explanation above, this research is focused on what is the basic philosophy that is the basis of the formulation and development of Islamic economics? This research data
\end{abstract}


is library. The data collection method uses the documentation method, namely: collecting, then reviewing the data collected. After the data is collected, the data is analyzed by reducing data, presenting data in narrative form, and drawing conclusions. This study concludes that the Islamic Economy is closely related to the maqashid syari'ah namely hifz al-mal. Maqashid syari'ah is the basis for the development of the Islamic economy because it aims at the goal of creating human welfare and happiness by balancing the circulation of property fairly and balanced both personally and socially. Understanding of maqashid syari'ah is a necessity in berijtihad to answer various economic problems. Understanding of maqashid syari'ah is not only needed to formulate macroeconomic policies, but also policies that are microeconomic. In the economic context, maqashid syari'ah has a dual role, namely: as a means of control as well as a social engineering tool to realize human equality. He provides a rational philosophical basis of economic activity. Without the maqashid syari'ah, the understanding and practice of Islamic economics will be narrow, rigid, static, and slow. Islamic economics will lose the spirit and substance of its sharia. But on the contrary, with the maqashid syari'ah the Islamic economy develops elastic, dynamic, in accordance with the character of the Shari'ah Islam which is universal and relevant for all space and time.

Keywords: Maqashid syari'ah, Mashlahah, Islamic Economics

\begin{abstract}
ABSTRAK
Berbeda dengan ekonomi kapitalis dan sosialis sekuler, Ekonomi Islam adalah ekonomi yang dibangun berdasarkan pada syari'ah, norma dan nilai-nilai ilahiyyah-transenden yang ada dalam teks-teks kegamaan (divine revelation), al-Qur'an dan ḥadiṣ. Agar dapat memahami essensi syari'ah, maka perlu dilakukan pergeseran paradigma (shifting paradigm) dari pendekatan literalis yang hanya mengacu pada makna tekstual dan legal ke pendekatan substansialis yang berusaha menangkap ideal moral dan makna asli (original meaning) syari'ah yang ada dibalik teks (beyond the text) yang bersifat transhistoris (transcendental being) dan universal (general principle). Pergesaran paradigma ini di dilakukan karena teks itu terbatas sementara realitas itu tidak terbatas. Diantara pendekatan subsatnsialis yang ditawarkan adalah penggunaan maqashid syari'ah. Maqashid syari'ah merujuk pada essensi maksud Tuhan (Law Giver) yang paling asasi yang dirumuskan menjadi 5 (lima) elemen, pemeliharaan terhadap agama, pemeliharaan terhadap jiwa, pemeliharaan terhadap akal, dan pemeliharaan terhadap keturunan dan pemeliharaan terhadap harta. Kemudian, secara hirarkhis, maqashid dalam teori klasik dikembangkan menjadi 3 (tiga) jenjang, yaitu: daruriyyat (kebutuhan primer), hajjiyat (kebutuhan sekunder), dan tahsiniyyat (kebutuhan tertier). Dengan argumen maqashid syari'ah inilah konsep ekonomi Islam harus dikembangkan, sehingga di satu sisi ekonomi Islam
\end{abstract}


tidak kehilangan moralitas ilahiyahnya, namun disisi lain ia juga dapat berkembang secara dinamis, progresif bahkan solutif dalam menghadapi problematika ekonomi kontemporer saat ini. Berdasarkan paparan di atas, penelitian ini difokuskan kepada apa basic filosofi yang menjadi landasan perumusan dan pengembangan ekonomi Islam? Data penelitian ini bersifat kepustakaan. Metode pengumpulan datanya menggunakan metode dokumentasi, yaitu: mengumpulkan, kemudian menelaah data yang dikumpulkan tersebut. Setelah data terkumpul kemudian dilakukan analisis data dengan cara reduksi data, penyajian data dalam bentuk naratif, dan menarik kesimpulan. Penelitian ini menyimpulkan bahwa ekonomi Islam berkaitan erat dengan maqashid syari'ah yaitu hị al al-mal. Maqashid syari'ah adalah dasar bagi pengembangan ekonomi Islam karena bertujuan tujuan untuk menciptakan kesejahteraan dan kebahagiaan manusia dengan menyeimbangkan peredaran harta secara adil dan seimbang baik secara personal maupun sosial. Pemahaman terhadap maqashid syari'ah merupakan sebuah keharusan dalam berijtihad untuk menjawab berbagai problematika ekonomi. Pemahaman terhadap maqashid syari'ah tidak saja diperlukan untuk merumuskan kebijakan-kebijakan yang bersifat makro ekonomi, tetapi juga kebijakan yang bersifat mikro ekonomi. Dalam konteks ekonomi, maqashid syari'ah memiliki peran ganda, yaitu: sebagai alat kontrol sekaligus alat perekayasa sosial untuk mewujudkan kemashlah atan manusia. Ia memberikan landasan filosofis yang rasional dari aktivitas ekonomi. Tanpa maqashid syari'ah, pemahaman dan praktik ekonomi Islam akan menjadi sempit, kaku, statis, dan lambat. Ekonomi Islam akan kehilangan spirit dan substansi syari'ahnya. Tetapi sebaliknya, dengan maqashid syari'ah ekonomi Islam berkembang elastis, dinamis, sesuai dengan karakter syari'ah Islam yang bersifat universal dan relevan untuk segala ruang dan waktu.

Kata-Kata kunci: Maqashid syari'ah, Mashlaḥah, Ekonomi Islam

\section{Pendahuluan}

Abul A'la al-Maududi (2005, 31-38) menyimpulkan bahwa sistem perekonomian di dunia ada 3 (tiga), yaitu: Kapitalisme, Komunisme, dan Islam. Kapitalisme berbasis pada individualisme dan liberalisme. Webster's (t.th), sebagaimana dikutip oleh Muhtadi Ridwan $(2011,76)$, mengatakan: "A system of economics in which private ownership of resources is permitted, along with the right to transact for personal profit)," dimana individu adalah pemilik tunggal dari apa yang telah diperolehnya, ia boleh menumpuk sarana produksi dan tidak membelanjakannya kecuali profitable. Implikasinya distribusi kesejahteraan sulit diwujudkan dan 
manusia terpolarsasi secara diametral antara The Have dan The Have Not. Kohesivitas sosial hilang dan bahkan terjebak pada dunia hampa norma (normlessness). Rasionalisme dan pragmatisme menserbabendakan segala hal dan rasionalitas ditempatkan lebih tinggi dari kepentingan orang lain (altruism), (Muhammad 2009, 1-3).

Sementar komunisme justru kontradiksi, ia hadir sebagai counter, antitesis yang mengkritik kapitalisme, dimana sarana produksi tidak boleh dimiliki secara individual melainkan milik bersama. 'Abdullah Zaky al-Kaf (2002, 49-51) dan Damsar (2015, 57) menyimpulkannya sebagai " $a$ theory or system of social organization based on the holding off all property in common." Individu hanyalah semacam alat mekanik produksi yang hanya menerima imbalan atas kontribusi, serta partisipasinya terhadap kepentingan sosial. Negara adalah pemegang kekuasaan hegemonik. Komunisme dan Kapitalisme berada dalam dua ujung yang bertentangan, namun sama-sama merupakan sistem tanpa etika (non value laden) dan sekuler.

Berbeda dengan sistem ekonomi komunisme dan kapitalisme, sistem ekonomi Islam membawa visi menegakkan "sistem moderat," yaitu sistem ekonomi yang bermoral ketuhanan (transcendental) sekaligus kemanusiaan (humanism), yang mencoba merestrukturisasi ekonomi pada nilai nilai original dan otentik (going back to the original Islam) yang pernah menjadi bentuk ideal (ideal type) pada masyarakat Islam awal. Islam menawarkan world view yang futuristik yang tidak hanya berorientasi jangka pendek (dunia) saja, melainkan juga jangka panjang (akhirat). Ia dibangun diatas prinsip keseimbangan antara materi dan immateri, rasional dan spiritual agar tidak terjebak pada hedonisme dan nihilisme (Harahap 2011, 1-10). Ekonomi yang dibangun di atas landasan prinsip, norma, dan nilai-nilai syari'ah seperti kejujuran, keadilan, serta kemashlahatan. Dalam konteks ini, Malik Firza dan Nabil Baydoun (2000), mengatakan:

Allah made the ummah of Islam an 'Ummatan Wasatan', one with the highest level of justice and a witness over mankind. This implies that all should acquire only the legitimate and profits made are just. Profits are permissible however not excessive in the expense of the society as this is regarded as exploitation. Individuals are encouraged to work hard to improve their economic standings but at the same time not to disregard 
the main principle that Allah is the Ownership of wealth hence, should also pursue for the betterment of the ummah. Islam advocates the just treatment of employees and the environment, trade in permissible businesses and trade quality products. Furthermore, Islam was once spread (among others) through the socially responsible Islamic traders.

Perbedaan diantara tiga sistem tersebut, menurut Dani Muhtada (2003) berangkat dari 3 (tiga) dimensi, yaitu: ontologi, epistemologi dan juga aksiologi, dengan penjelasan sebagaimana berikut:

Sistem ekonomi

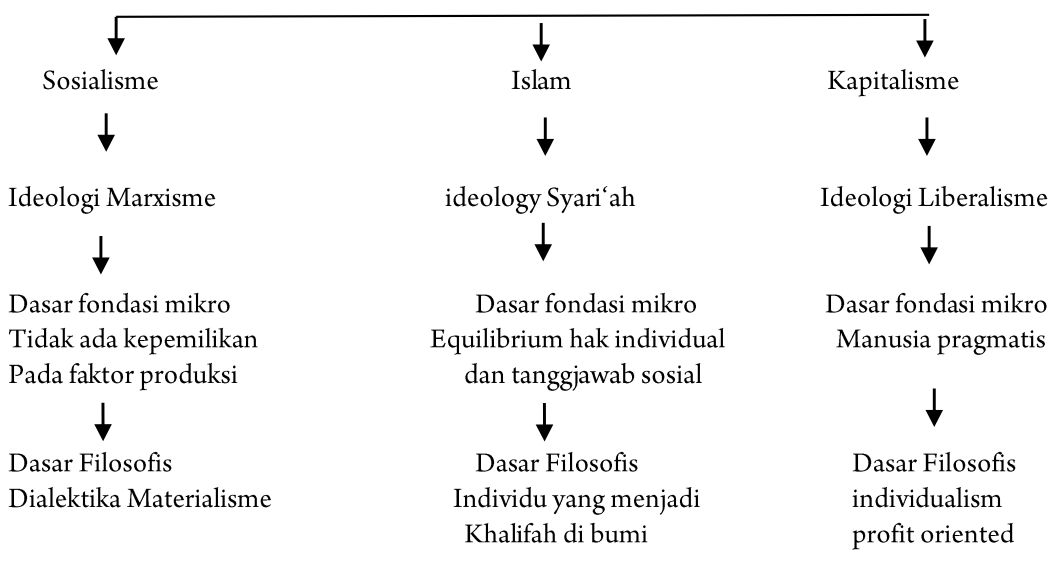

Hanya saja, masih banyak yang meragukan eksistensi sistem ekonomi Islam, benarkah ia memang merupakan sistem yang berbeda dari system yang lainnya, ataukah ia hanya sekedar sikap reaktif umat Islam dalam menyikapi perekomomian dunia saat ini (Muhtada 2003). Kalau memang benar, ia ada, bagaimana dan atas dasar apa ia bisa dikembangkan.

Berdasarkan paparan di atas, penelitian ini difokuskan kepada apa basic filosofi yang menjadi landasan perumusan dan pengembangan ekonomi Islam?

Data penelitian ini bersifat kepustakaan. Metode pengumpulan datanya menggunakan metode dokumentasi, yaitu: mengumpulkan, kemudian menelaah data yang dikumpulkan tersebut. Setelah data terkumpul kemudian dilakukan analisis data dengan cara reduksi data, 
penyajian data dalam bentuk naratif, dan menarik kesimpulan (Miles and Huberman 2009, 16).

\section{Syari'ah: Antara Pendekatan Tekstual dan Substansial}

Syari'ah adalah norma Ilahi yang menyangkut credo maupun perilaku manusia dalam berbagai dimensi hubungan, baik individual maupun sosial yang terdokumentasikan dalam al-Quran dan hadiṣ. Dalam perjalanan sejarahnya, pemahaman syari'ah bercorak teologis deduktif dan induktif analitis. Keduanya sama-sama berparadigma literalistik. Pembahasan keduanya lebih dititikberatkan pada teks baik secara grammar maupun semantik dan mengabaikan pembahasan tentang maksud dan tujuan yang ada di balik teks. Paradigma ini berlangsung dari abad 2 sampai $7 \mathrm{H}$. Pada abad $8 \mathrm{H}$. mulai ada upaya melakukan pergeseran paradigma (shifting paradigm) dengan menawarkan maqashid syari'ah yang merujuk pada essensi maksud Tuhan (Law Giver) yang paling asasi dan tidak berpaku pada jebakan literalisme teks (M. A. Abdullah 2007, ix).

Maqashid kemudian direvitalisasi 'ulama' berikutnya untuk menghadapi problematika kekinian yang semakin komplek dengan memadukan pola pikir fikih klasik dan modernitas. Mereka dikategorikan sebagai yang bermażhab utilitarianisme atau substansialisme. Dalam pandangannya, teks-teks keagamaan (divine revelation), al-Qur'an dan hadiș, harus dipahami dalam hubungan relasional intrinsiknya dengan ideal moral yang bersifat universal (gerenal principle), antara makna otentik (original meaning) dengan legal spesifik yang bersifat particular dan temporal, sehingga terbangun rumusan pandangan dunia al-Qur'an (Qur'anic Weltanshauung) yang moderat dan tidak kering dan rigid (a dry legalism).

Dalam paradigma baru tersebut, hubungan teks dengan realitas historis sering didudukkan secara binner pada posisi diametral, direkonstruksi menjadi hubungan yang bersifat dialektis karena realitas itu tidak terbatas sementara teks itu terbatas (M. A. Abdullah 2012, 166), ان النصوص تتناهي و لكن الحوادث لا تتناهي (Zahrah 2009, 16). Pergeseran paradigma (shifting paradigm) ini dilakukan sebagai upaya untuk menginterprestasikan seluruh nilai (value) yang benar-benar 
dapat disebut moral yang memiliki dimensi norma yang ekstra dan transhistoris (transcendental being) pada era modern yang jelas berbeda dan memiliki karakteristik dengan masyarakat Islam awal (M. A. Abdullah 2004, 137). Juga karena konsekuensi pola fikir tekstualis-normatif memunculkan respon dan sikap defensif-apologetik dan tindakan kontra-produktif yang justru membuat umat Islam acap kurang kritis mengantisipasi laju perkembangan, termasuk persoalan ekonomi.

Pendekatan substansialis ini berdasarkan pemikiran bahwa dinamika realitas tetap harus mengikuti syari'ah Tuhan tetapi bukan secara tekstualis, melainkan secara substansialis karena syari'ah-lah yang memberi spirit dan nilai. Perubahan dan dinamika realitas dalam bentuk apapun tetap dapat diakomodasi syari'ah yang universal. Namun, sebagaimana dinyatakan oleh Amir Mu'allim $(2008,150)$ bahwa syari'ah harus tetap sebagai pengendali gerak realitas agar tetap berporos padanya, disamping ia akan memberikan nilai dan makna (meaning) terhadap perubahan realitas itu sebagaimana digambarkan sebagai berikut:

\section{Realitas kehidupan yang selalu} berubah dan berkembang

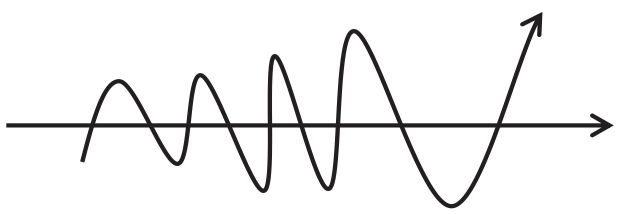

Maqāṣid as-syarī‘ah yang tetap dan universal

Dalam konteks diskursus ekonomi syari'ah, dua pendekatan, baik tekstualis dan substansialis harus digunakan secara proporsional dan simultan. Hal ini dikarenakan ekonomi syari'ah bukanlan ekonomi sekuler yang didasarkan pada pemikiran manusia an-sich melainkan adalah ekonomi yang didasarkan pada nilai-nilai transendental yang bersumber dari teks-teks al-Qur'an dan hadiṣ. Hanya saja, teks itu terbatas sementara persoalan ekonomi manusia terus berjalan dinamis bahkan progresif. Karena itu pendekatan substansialis, penerapannya menjadi sangat penting. 


\section{Mashlaḥah Sebagai Maqashid Syari'ah}

Maqashid syari'ah adalah tujuan esensial diturunkannya syari'ah ('Audah 2015, 31). 'Allal al-Fasi (1963, 3) dalam kitab Maqashid as-Syari'ah al-Islamiyah wa Makarimuha mendefinisikan maqashid

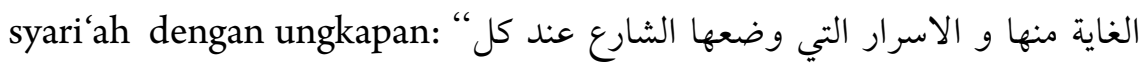
(Tujuan dan rahasia syariah yang telah diletakkan oleh pembuat hukum [Syari'] pada setiap hukum-hukumnya) dan ArRaisuni dalam kitab Nażariyyat al-Maqashid 'Inda al-Imam as-Syațibi (الغابات التي وضعت الشريعة " الاجل تحقيقها لمصلحة العباد (Tujuan-tujuan yang telah diletakkan oleh syari'ah untuk diselidiki demi kemashlahạatan manusia).

Maqashid syari'ah, Secara hirarkhis, dalam teori klasik terbagi ke dalam 3 (tiga) tingkatan, yaitu: الضرورية(primer), الحاجية (kebutuhan), dan التحسينية (tertier) (Yasid 2007, 12-14). Secara sederhana, maqashid syari'ah, juga dapat di bagi menjadi mashlahahah ḍaruriyyah مصلحة الضحة dan gairu daruriyyah (مصلحة غير الضرورية), dengan essensi yang sama (Husain 2013, xv).

Daruriyyah merupakan tingkatan kebutuhan manusia yang esensi dan inti, yang apabila tidak terpenuhi menjadi hilang eksistensi manusiawinya. Oleh karena itu tingkatan ini menghendaki adanya realisasi dalam konteks kehidupan nyata serta penjagaan terhadap eksistensinya. Daruriyyah secara hirakhis dirumuskan al-Gazali dan dikuatkan kembali oleh as-Syatibi menjadi 5 (lima) kebutuhan dasar, yaitu: menjaga agama, menjaga jiwa, menjaga akal, menjaga keturunan, dan menjaga harta.

Hajjiyyah adalah kebutuhan yang menunjang eksistensi ḍaruriyyah yang sifatnya penting walaupun tingkatannya ada di bawahnya, seperti: persamaan, keadilan, dan kemerdekaan. Sedangkan taḥsiniyyah adalah kebutuhan selain primer dan sekunder, yang perlu diwujudkan dan dipelihara untuk kesempurnaan hidup manusia, seperti: cara berpakaian, bergaul, dan lainnya. 


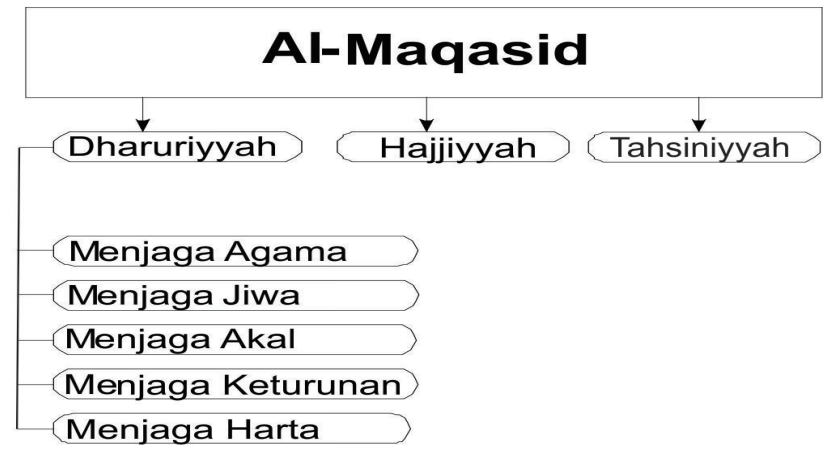

\section{Gambar: skema maqashid syari'ah ditinjau dari perspektif Keniscayaan}

('Audah 2013, 9).

Secara implementatif, sesuai hirarkhisnya maka menjaga ḍaruriyyah harus lebih didahulukan daripada hajjiyah, taḥsiniyyah, dan seterusnya. Karenanya, jika tidak dilaksanakan, maka kehidupan manusia akan menghadapi bahaya, seperti: menjaga agama, jiwa, akal, dan lainnya. Penjagaan selanjutnya adalah hajjiyah karena tingkatan keniscayaannya berada di bawah daruriyyah. Ketidaksediaannya pada tingkat individu bukanlah menyangkut masalah hidup dan mati, seperti: menikah, berdagang, dan lainnya. Penjagaan terakhir adalah tahsiniyyah, kebutuhan yang dapat memperindah kehidupan, seperti bergaul dengan memakai pakaian yang bagus (Al-Qarḍawi 2006, 29).

Pengetahuan mengenai tingkatan kemashlahatan dan karakteristiknya adalah sangat penting terutama untuk menetapkan hukum pada tiap-tiap perbuatan dan persoalan yang dihadapi manusia. Contohnya memelihara jiwa yang bersifat daruriyyah yang hukumnya adalah Hukum ini tidak berubah kecuali jika dihadapkan pada persoalan lain yang sifat ḍaruriyyahnya lebih tinggi, seperti memelihara agama. Jiwa dapat dikorbankan demi memelihara agama, dan seterusnya (Haq 2007, 105).

Dengan kata lain dalam implementasinya, jika didapat hal-hal yang kontradiktif, maka ḍaruriyyah harus didahulukan dari hajjiyah dan taḥsiniyyah, dan hajajiyah harus didahulukan dari taḥsiniyyah. Hal ini karena esensi agama seringkali dijabarkan dalam teks-teks syari'ah partikular, namun yang partikular berjalan dalam kerangka yang global. اصول Jika ada kontradiksi, maka فرو (cabang) harus dikembalikan pada 
(pokok), متغيرة (dinamis-temporal) kepada ثوابت (statis-universal), dan محكمم (ambigu) ke متشبه (pasti) (Al-Qardawi 2006, 29).

Walaupun maqashid disusun secara hirarkhis sesuai dengan kriteria masing-masing, pada faktanya masih terjadi hubungan keterkaitan bahkan persimpangan di antara ketiganya, misalnya pernikahan dan perdagangan yang adalah hajjiyah masih berkaitan erat dengan pemeliharaan agama dan keturunan, sebagaimana dapat dipahami pada gambar di bawah ini:
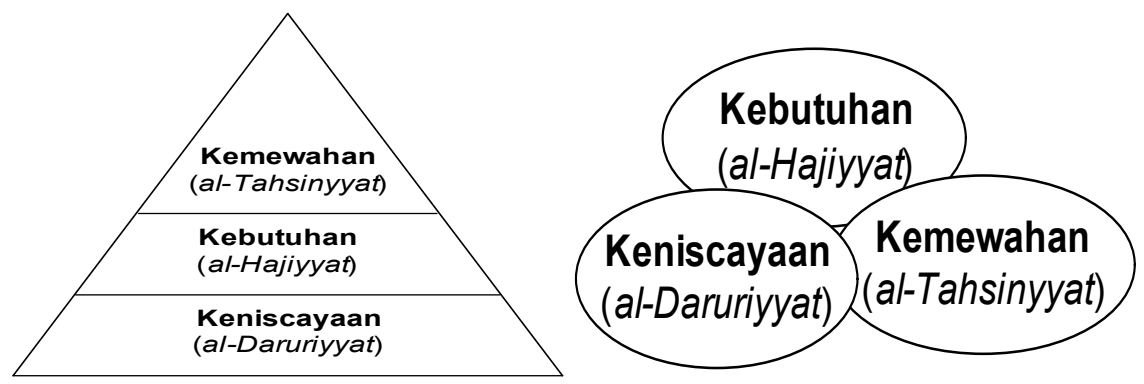

Gambar : Maqashid dilihat dari Hierarkhi, Persimpangan, dan Keterkaitan antar maqashid ('Audah 2013, 12-13).

Pada gambar di atas, sebagaimana dijelaskan oleh A. Halil Tahir dalam buku Ijtihad Maqashidi, Rekonstruksi Hukum Islam Berbasis Interkoneksitas Mashlaḥah $(2015,72)$ bahwa setiap dimensi maqashid memiliki domain dan wilayah sendiri, namun terjadi hubungan interdependensi dan interkoneksi antara satu dengan yang lain, seperti: agama sebagai prioritas tertinggi tidak akan terwujud tanpa keberadaan jiwa, akal, keturunan dan harta sebagaimana gambar berikut:

Bagan

Interkonektisitas masalah (Ittisaliyat al-masalih)

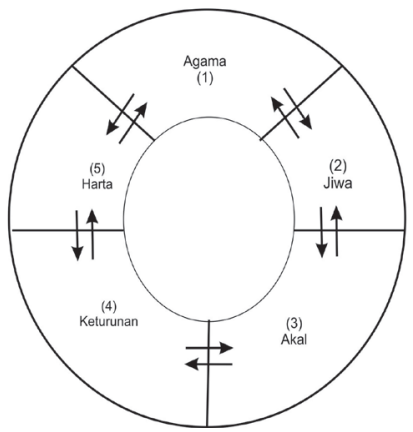


Sebagian 'ulama' menyamakan mashlahah dengan maqashid syari'ah ('Audah 2015, 6-7), karena akhir dari seluruh rangkaian tujuan syari'ah (maqashid syari'ah) tak lain adalah terimplementasinya kemashlahatan manusia di dunia dan akhirat (Koto 2014, 148).

Setiap teks agama mempunyai keterkaitan (relasi) bahkan interrelasi dengan kemashlahatan manusia. Walaupun para ahli tidak mencapai sepakat dalam memberikan batasan kemashlahatan, namun secara substansi mereka sepakat bahwa mashlahah adalah upaya untuk mendatangkan sesuatu yang berdampak manfaat serta menghindari madarat (Yasid 2007, 130-35).

Kriteria mashlahah adalah tegaknya kehidupan dunia demi tercapainya kehidupan akhirat. Syari'ah bukanlah bermaksud menempatkan manusia dalam penguasaan eksploitatif atas nama hukum agama, namun syari'ah memang diadakan untuk kemashlah atan. Dengan demikian mashlahah bersifat universal, berlaku umum dan abadi atas seluruh manusia dan dalam segala keadaan (Haq 2007, 83). Dalam konteks ini, Mohammed Obaidullah dalam tulisannya yang berjudul: "Ethics and Efficency In Islamic Stock Markets," dalam International Journal of Islamic Financial Services, Volume 3, No.2, (2001), mangatakan:

Mashlahah mursalah is a valid framework of Islamic legislation. The framework is called "unrestricted" public interest on account of its being undefined by the established rules of Shariah. Mashlahah consists of "considerations which secure a benefit or prevent a harm but are, in the mean time, harmonious with the objectives (maqashid) of Shariah. These objectives consist of protecting five essential values, namely, religion, life, intellect, lineage and property, which have a much wider scope and meaning. For instance, protecting the right to live includes protecting the means, which facilitate an honorable life, such as, freedom to work and travel. Protection of property requires defending the right of ownership. It also means facilitating fair trade and lawful exchange of goods and services in the community. Any measure which secures these values falls within the scope of mashlahah and anything which violates them is mafsadah (evil), and preventing the latter is also mashlahah".

Secara garis besar mashlaḥah ada 3 (tiga) macam (Supriyadi 2014, 229); (S. E. M. Zein 2009, 97), yaitu: mashlahahah mu'tabarah, yaitu: mashlaḥah yang ada dalil syara'nya. Mashlahạ ini berkaitan dengan menjaga agama, jiwa, akal, keturunan, dan harta; mashlaḥah mulgah, 
yaitu mashlahah yang dibatalkan oleh nash seperti wanita sebaiknya mendapatkan bagian waris sama dengan pria, namun ini dibatalkan oleh nash bahwa bagian perempuan itu setengahnya laki-laki; maṣla nash hah mursalah, yaitu mashlahah yang tidak ditetapkan dan juga tidak ditolak oleh nash atas dasar memelihara kemashlahatan.

Mashlahah yang tidak ada nash ini, para ulama memiliki perspektif berbeda dalam meletakkan ukuran nilai (value); ada yang diukur berdasarkan kesempurnaan, keadilan, dan kemoderatan ('Abdul Mun'im Shaleh 2012, 63).

Menurut al-Gazali $(450-505 \mathrm{H})$ ukuran mashlahah tidak dapat dikembalikan kepada penilaian manusia karena itu sangat rentan diintervensi nafsu, terjebak pada absurditas, dan akan mengeneralisasi mashlahah tanpa batas. Sedangkan mashlaḥh itu sendiri sering terfragmentasi pada peristiwa hukum yang di dalamnya tercover mafsadah. Jadi mashlaḥah disamping harus daruriyyah, juga harus qațiyyah dan kulliyyah, mendesak, pasti, dan menyangkut kepentingan umum bukan individual ('Abdul Mun'im Shaleh 2012, 77). Karenanya, sebagaimana dikutip oleh Ahmad Munif Shaleh $(2012,109)$ dan Hạalil Tahir $(2015,68)$ al-Gazali mengatakan:

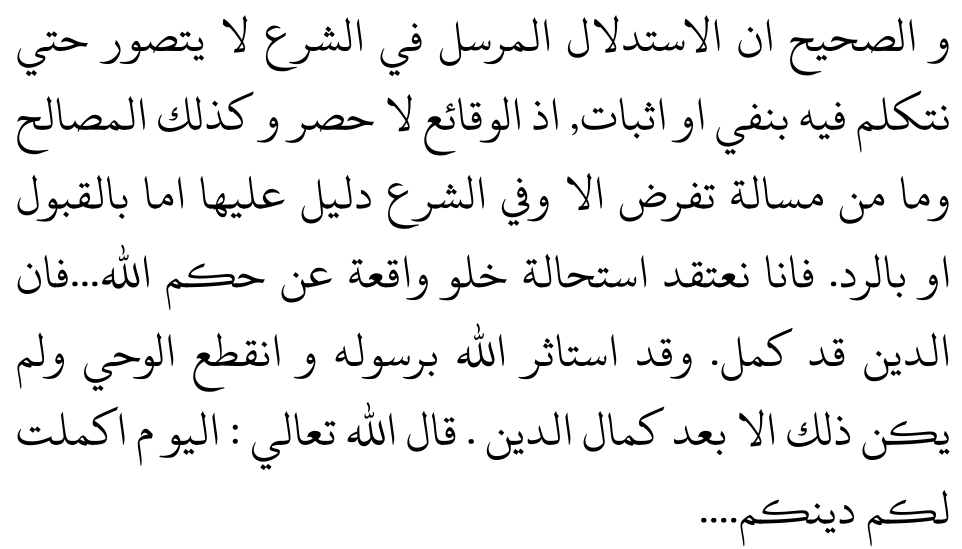

Al-Gazali dapat menerima mashlaḥah sepanjang tidak bertentangan dengan tujuan syara' dan ia disimpulkan dari dalil yang tak terhitung, baik dari al-Qur'an, as-sunnah, situasi dan kondisi, serta indikator lain, sebagaimana dikutip Ahmad Munif Shaleh $(2002,65)$, di bawah ini: 
كل مصلحة رجعت الي حفظ مقصود شرعي علم كونه

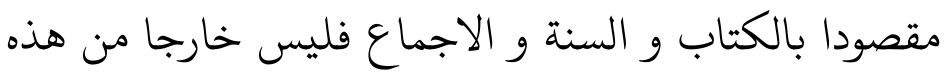

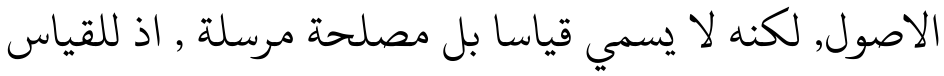
اصل معين و كون هذه المعاني وقصودة عرفت لا لا بدليل

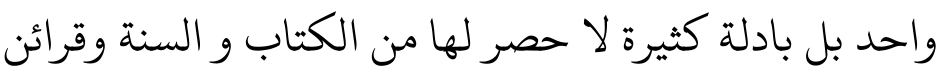
الاحوال و تفاريق الامارات تسمي لذلك بلك مصلحة مرسلة

At-Ṭuf $(657-716 \mathrm{H})$ berpandangan bahwa mashlahah merupakan prinsip pertama syaríah bahkan terkesan dapat melampaui nash (As- Syayihi 1993, 23-25):

ثم ان قول النبي ( لا ضرر ولا ضرار ) يقتضي رعاية المصالح اثباتا و نفيا و المفاسد نفيا , اذ ضرر هو المفسدة, فاذا نفاها الشرع لزم اثبات النفع الذي هو المصلحة لاديا لانهما نقيضان

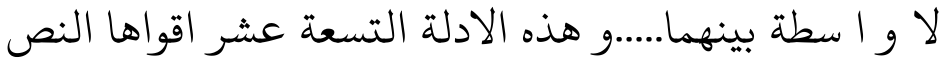

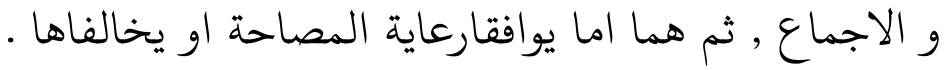
فان واقافها فبها و نمعت ولا تنازع,اذ تفقت الادلة الثلاثة

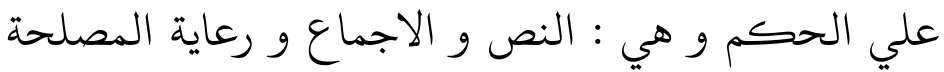

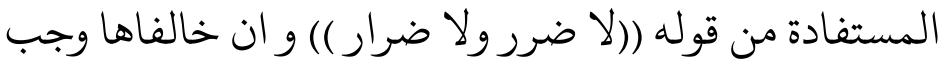
تقديم المصلحة عليهما بطريقة التخصيص و البيان لهمالا

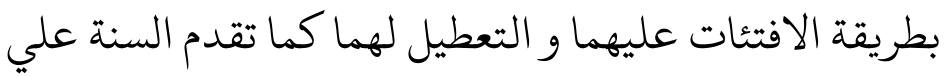

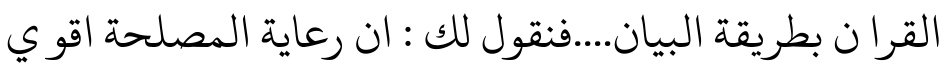

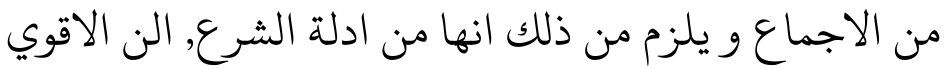
من الاقوي اقوي... - من الاجيا

Menurut at-Tufi kemashlaḥatan manusia (human welfare) harus atau mesti mendapat prioritas di atas bentuk teks-teks. Perlindungan terhadap kemashlahatan manusia adalah tujuan utama syari'ah (maqashid syari'ah), sehingga ia tidak layak digantikan oleh sumber hukum lain 
yang kurang meyakinkan religius ('Amiri 2004, xvii). Hanya saja ini tidak berkaitan dengan hukum ibadah, tetapi bekaitan dengan mu'amalat yang makna dan maksudnya dapat dijangkau oleh akal, sehingga landasan hukumnya adalah mashlaḥah baik saat ada nash maupun tidak ada (A. M. Shaleh 2002, 87).

Pemberian prioritas kepada kemashlahatan manusia menurut at-T. ufi tidak dimaksudan untuk menghentikan atau menyangkal secara total validitas al-Qur'an dan hadis tapi hanya untuk menjelaskan fungsinya yang proporsional. Didahulukannya mashlahah dibandingkan teks keagamaan disebabkan teks itu kadang bersifat mutawatir kadang bersifat aḥad, ada yang jelas (sharih) dan ada yang ekuivokal (muhtamal). Dalam konteks inilah, kemashlahatan manusia dipandang lebih kredibel dibandingkan teks, karena lebih riil dan substansiil. Namun menurut Yusuf Qarḍawi, bukan berarti at-Ṭu mengabaikan teks sebagai dalil syara' yang paling otoritatif, karena menurutnya tidak mungkin teks yang qaț i i bertentangan dengan mashlaḥah. Bahkan, Ahmad 'Abdurrah im as-Syayihi dalam kitab Risalah fi Ri'ayah al-Mashlahah li Imam at-T. ufi $(1993,38)$, menyimpulkan bahwa menurut at-Tufi menjaga mashlah ah dengan cara meninggalkan dalil syara' itu dilarang, sebagaimana pernyataannya di bawah ini:

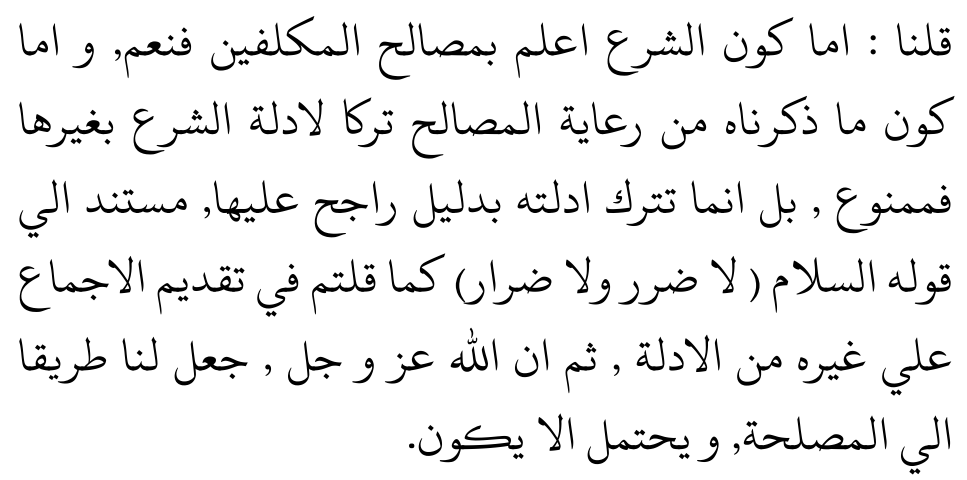

At-Ṭu tidak meninggalkan dalil syara' ketika menentukan mashlahah, hanya mencari dalil yang lebih kuat (rajih). Karena menurut at-Ṭufi teks zanni bisa dikhususkan dengan kemashlahatan qat'i $i$. Artinya, bukan berarti kemashlahatan dapat menganulir teks agama, tapi hanya memuqayyadkan (Al-Qarḍawi 2006, 136); atau dilakukan proses pembatasan (takhshish) dan keterangan (bayan), tidak 
dengan menyerang mashlahah tersebut, sebagaimana sunnah terkadang didahulukan dari al-Qur'an dalam konteks bayan dan takhshish tersebut (Muslehuddin 1997, 133). Sementara as-Syatibi (w. 790 H) juga dapat menerima dengan syarat adanya mashlaḥah tersebut tidak diketahui dari suatu dalil khusus saja, tetapi melalui kumpulan dalil yang memberi kaidah qaț $i$ sebagaimana dikutip Aḥmad Munif Shaleh (2002, 67) berikut ini:

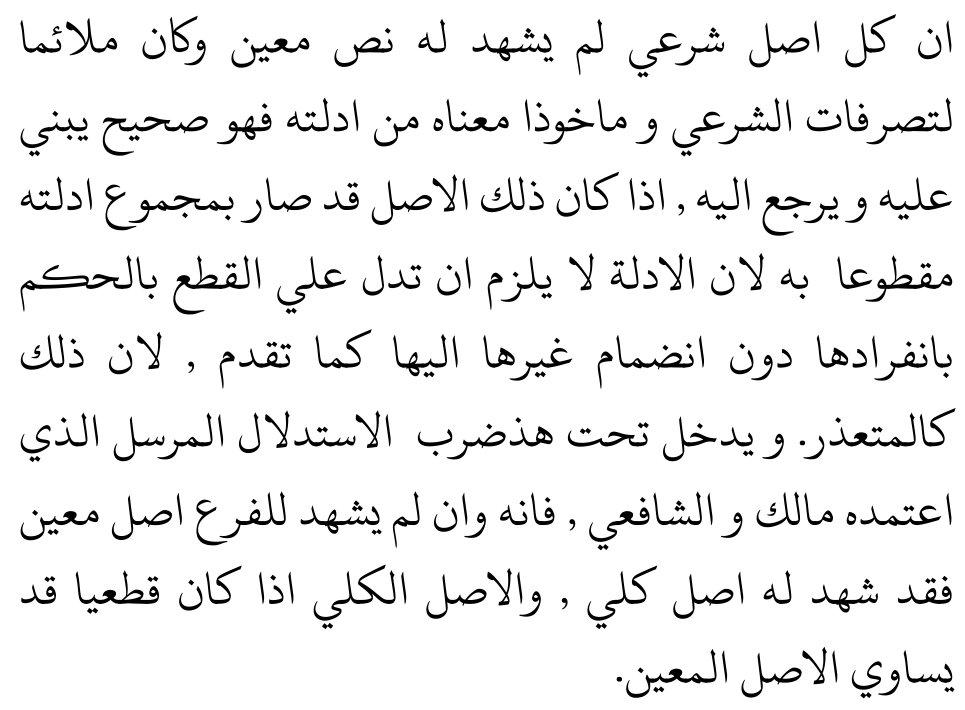

\section{Maqashid Syari'ah Sebagai Dasar Pengembangan Ekonomi Islam}

Saat ini umat Islam dihadapkan pada persoalan-persoalan ekonomi kontemporer akibat perkembangan peradaban manusia dan kemajuan Ilmu Pengetahuan dan Teknologi (IPTEK). Maraknya ragam kegiatan ekonomi dengan berbagai bentuknya yang kompleks memunculkan problem hukum Islam dikalangan para pakar hukum Islam. Problem hukum Islam ini tidak boleh dihadapkan secara konfrontatif dengan teks yang tidak menjelaskannya, namun harus diselesaikan secara ijtihadi, karena Islam telah memberikan desain normatifnya secara global. Ijtihad ini merupakan usaha aktif, kreatif, solutif, dan produktif dalam membangun kehidupan ekonomi. Karena problem hukum dalam bidang mu'amalah selama masih diketahui tujuan hukumnya (maqashid syari'ah) dapat dilakukan pengembangan hukum. 
Menurut Syafrudin Prawiranegara, sesungguhnya ekonomi itu dimana mana sama saja, yang membedakannya hanyalah moral saja. Sedangkan Musa Asy'ari berpandangan bahwa ekonomi adalah bagian dari kebudayaan, karena ia integral dengan sistem nilai, baik teologi, kosmologi, mapun antropologi. Ekonomi dan sistem nilai ini sulit dipisahkan karena menyangkut pengetahuan dan pengalaman manusia yang paling abstrak hingga transaksi harian yang paling detail. oleNah, persoalan ekonomi itu bersumber dari moral-etiknya dan ekonomi yang ditawarkan Islam adalah ekonomi yang dikembangkan berdasarkan moralitas Islam. Hal ini karena al-Qur'an adalah wahyu yang dari awal sampai akhir selalu memberi tekanan-tekanan moral yang diperlukan dalam kehidupan (M. A. Abdullah 2015, 70; Asy'arie 2015, 5-9; Rahman 1984). Dalam konteks ini, Malik Firza dan Nabil Baydoun (2000: 5), mengatakan:

Businesses in the Islamic society are no different. They are expected to adhere within the legal framework of the country and its political environments. In Islam, trading is highly honoured as Allah proclaims (An Nisa 4:33). Islam permits reasonable profits, though not excessive to prevent exploitation. The Western world recognises Corporate Social Responsibility while Islam goes beyond the social context where Allah is the ownership of all wealth.

Menurut 'Abdul Manan ekonomi Islam adalah ilmu pengetahuan sosial yang mempelajari masalah ekonomi yang diilhami oleh nilainilai rabbaniyyah. Selanjutnya Hasanuzzaman mengartikan sebagai pengetahuan dan penerapan perintah-perintah (injunctions) terhadap norma dan aturan (rules) yang ditetapkan syari'ah yang menghindari dan mencegah ketidakadilan dalam penggunaan sumber daya material guna memenuhi kebutuhan ekonomi; artinya sasaran kajian ekonomi Islam adalah alokasi sumber daya matrial yang merupakan pilihan rasional (rational choice) yang dibingkai oleh aspek syari'ah sebagai muatan normatifnya (Mufid 2016, 118-32).

Nilai-nilai esensial mashlaḥah sebagai maqashid syari'ah ini dapat dipakai untuk merumuskan ekonomi dalam konteks kekinian, baik dalam proses produksi, konsumsi, distribusi, kebijakan fiskal, keuangan, lembaga keuangan, dan sebagainya (Mufid 2016, 118-32). Al-Qur'an dan 
hadiṣ sebagai teks syari'ah secara garis besar telah menentukan prinsipprinsip umum dalam kegiatan ekonomi dengan tujuan menciptakan struktur ekonomi yang berkeadilan di atas nilai-nilai keseimbangan dan kemashlahatan tanpa unsur eksploitasi, dimana syari'ah difungsikan sebagai pengontrol dan perekayasanya (Aziz 2013, 6; Ghofur 2017, 58), sebagaimana penjelasan berikut:
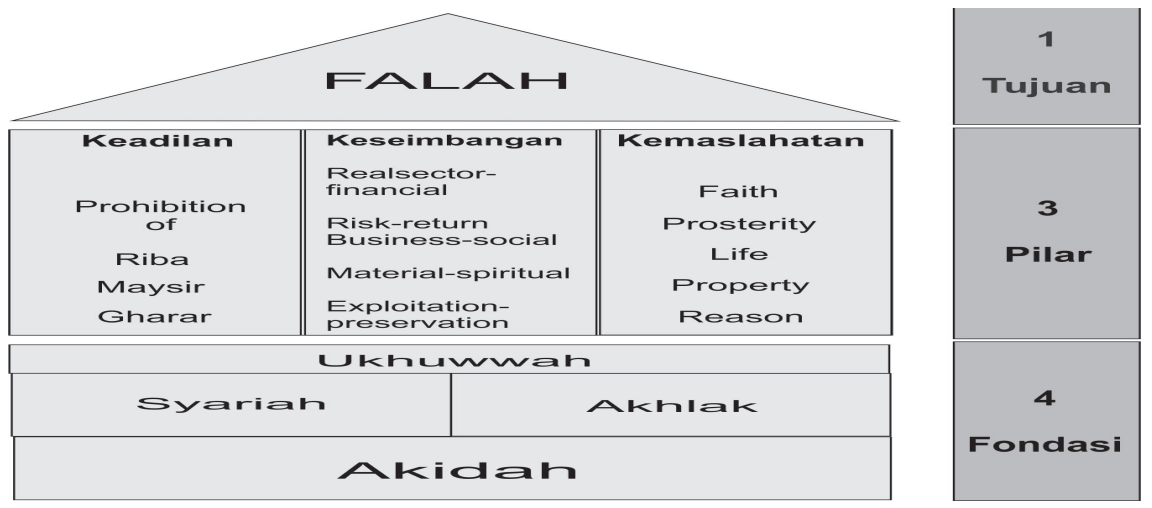

Tujuan hidup dalam Islam adalah bahagia dan mulia (falah) dalam segala dimensi dan komprehensif baik secara material maupun spiritual, individual maupun sosial, dunia maupun akhirat. Ekonomi adalah salah satu instrumen yang diharapkan mampu membawa manusia kepada tujuan hidup tersebut. Dalam konteks dunia, falah merupakan konsep yang multidimensi yang memilki implikasi pada aspek perilaku individual/mikro maupun perilaku kolektif/makro.

Falah, hidup bahagia dan mulia dunia dan akhirat, dapat terwujud jika kebutuhan hidup tercukupi secara seimbang. Ketercukupan kebutuhan tersebut akan membawa efek yang disebut mashlaḥah yaitu segala bentuk keadaan, baik material maupun non material yang mampu meningkatkan kedudukan manusia sebagai makhluk paling mulia. Mashlaḥah dasar/ḍaruriyyah bagi manusia menurut al-Gazali dan as-Syatibi sangat dibutuhkan baik untuk kehidupan duniawi maupun ukhrawi (Praja 2015; UII 2008, 4-7)

Maqashid syari'ah mengandung semua hal yang diperlukan manusia untuk mencapai falah secara syari'ah. Al-Gazali menempatkan hị ad-din pada urutan pertama karena atas dasar itulah manusia akan meletakan dan merumuskan relasi-relasi kemanusiaan dalam perspektif 
dan filter moral pada pondasi yang benar. Hal itu memungkinkan manusia dapat berinteraksi secara adil. Iman akan memberikan instruksi dan guidline moral tentang alokasi, produksi, konsumsi dan distribusi dalam bingkai keadilan, keseimbangan dan kemashlahatan. Kemudian al-Gazali menempatkan hifẓ al-mal pada urutan paling akhir karena secara ideologis harta bukanlah tujuan. Ia hanya instrumen untuk mencapai falah. Karena harta tidak mungkin merealisasikan falah, jika ia tidak menyertakan kriteria moral dalam alokasi dan distribusinya. Jika harta adalah tujuan maka akan sangat lekat dengan eksploitasi dan kezaliman (Chapra 2000,7-10). Sementara tiga maqashid lainnya yaitu: ḥifẓ nafs, ḥifẓ al-ál, dan ḥifẓ an-nasl, pencapaian kebahagiaanya menjadi tujuan utama dari syari'ah yang harus dilindungi dengan komitmen moral. Ketiganya tidak mungkin terlindungi di dunia yang sekuler. Semua hal yang digunakan untuk melindungi ketiganya harus dianggap sebagai sesuatu yang bersifat hajjiyah seperti makanan, sandang, papan, pendidikan intelektual, lingkungan sehat, kesehatan, transportasi yang aman, dan lainnya.

Ada sebuah ilustrasi yang menarik dan relevan untuk menjelaskan ini, yaitu: "Ketika Yusuf Qarḍawi ditanya sahabatnya yang mengajar di berbagai perguruan tinggi di Barat: 'Apakah anda memiliki keyakinan bahwa Islam memiliki sistem ekonomi yang berbeda dengan sistem lain'?" Beliau memberikan 2 (dua) jawaban. Pertama, tidak ada, jika yang dimaksud sistem itu adalah aturan dalam bentuk yang rinci dan detail. Kedua, ada, jika sistem itu adalah prinsip, nilai, dan moral yang global-universal. Islam selalu menerapkan aturan yang bersifat kulli untuk persoalan-persoalan yang memiliki potensi untuk berubah searah dengan dinamika ruang dan waktu. Sedangkan untuk persoalan yang tidak mengalami perubahan, aturan Islam bersifat juz'i, sangat detail dan rinci. Ekonomi adalah wilayah yang sangat dinamis, karena itu detail dan rincinya merupakan medan ijtihad (Hakim 2011, 40-41).

Dalam persoalan ekonomi, Islam lebih banyak memberikan prinsip dan kaidah umum dibandingkan menjelaskan secara detail sebagaimana kaidah الاصل في المعاملة الاياحة الا ما دل علي تحريمها. Atas dasar inilah perkembangan teknis dan mekanisme mu'amalah diserahkan sepenuhnya kepada para ahli di bidangnya. Bidang ekonomi di atas menjadi domain 
taaqquliyyat atau ma'qulatul ma'na, sesuatu yang dapat di nalar. Jika ia dikembangkan sesuai dengan substansi yang dikehendaki syara' dan bertujuan untuk kemashlaḥatan manusia serta meninggalkan kemuḍ aratan, maka ia dapat diterima berdasarkan kaidah: تغير الفتوي و اختلافها بحسب الازمنة و الامكنة و الاحوال والنيات (Mardani 2015,6).

Maqashid syari'ah adalah metodologi berfikir guna menjembatani 2 (dua) domain antara worldview Islam dan worldview ilmiah, antara teks dan konteks empirik untuk menemukan hakekat syari'ah. Maqashid juga memiliki potensi untuk menjembatani antara kaum yang punya (haves) dan kaum tidak punya (have nots). Penjembatan itu bukan sekedar gerakan charity (amal) untuk bersedekah sehingga terjadi trickle down effect, tapi maqashid diintegrasikan dengan worldview al-Qur'an dan ilmu kontemporer seperti kebijakan publik, pemberdayaan ekonomi, dan lainnya, yang dapat menyarankan solusi-solusi struktural yang tuntas ('Audah 2013, x).

Pemahaman terhadap maqashid inilah yang selama ini dijadikan landasan merumuskan dan menjawab problematika kehidupan ekonomi yang dihadapi setelah Nabi SAW wafat, misalnya: Abu Bakar ra. merumuskan kebijakan zakat dan penggajian pegawai; Umar bin al-Khat tab ra. membuat kebijakan tentang pencetakan uang, pengembangan pertanian, pajak perdagangan dan tanah, kebijakan fiskal, pendirian addiwan, komite sensus, hukum perdagangan; 'Ali bin Abi Thalib mencetak uang atas nama pemerintah Islam yang sebelumnya menggunakan dinar Romawi dan dirham Persia. Kemudian disusul oleh para 'ulama' seperti: Abu Hanifah $(80-150 \mathrm{H})$ tentang konsep jual beli salam dan zakat pertanian; Abu Yusuf (113-182 H) yang menulis Kitab al-Kharaj yang berisi tentang perpajakan, keuangan negara, pertanahan dan lainnya. Ia meletakkan kaidah: الامام علي الرعية منوط بالمصلحة تصرف; Ibnu al-H asan as-Syaibani membahas tentang ijarah, tijarah, zira'ah, dan shina'ah dalam Kitab al Iktisab fi ar-Rizq al-Mustahab; Abu 'Ubaid al-Qasim (w. $224 \mathrm{H}$ ) menulis Kitab al-Amwal yang membahas tentang zakat, khums, kharaj, fai'; Hariș bin Asad membahas tentang perdagangan, industri, dan kegiatan ekonomi produktif; Ibnu Miskawaih (w. $421 \mathrm{H}$ ) yang membahas tentang pertukaran barang dan jasa dalam Tahżib alAkhlaq; al-Mawardi (w. $450 \mathrm{H}$ ) banyak menyinggung tema ekonomi 
dalam Kitab al- Akam as-Sultaniyyah dan Adab ad-Diin wa ad-Dunya; alGazali (451-505 H) banyak membahas ekonomi dalam karya-karyanya; Ibnu Taimiyyah $(661-728 \mathrm{H})$ membahas tentang peran negara dalam ekonomi umat; Ibnu Khaldun (732-808 H) banyak menulis tentang perdagangan internasional, konsumsi, produksi, dan lainnya; Muh ammad Iqbal yang membahas tentang keadilan ekonomi dan lainnya (B. Abdullah 2010; Chamid 2010; Karim 2011; UII 2008).

Menurut Anas Zarqa, sebagaimana dikutip oleh Abdul Ghofur, menegaskan bahwa ekonomi Islam itu terdiri dari 3 (tiga) kerangka metodologi. Pertama, presumption and ideas atau prinsip dasar ekonomi yang bersumber dari al-Qur'an, hadiș, dan fiqh al-maqashid. Kedua, nature of value jugdgement, yaitu pendekatan nilai dalam Islam terhadap situasi ekonomi yang terjadi. Ketiga, positive part of economics science, yaitu pengilmuan Islam supaya compatible direalisasikan secara empirik ekonomi. Berdasarkan 3 pendekatan inilah ekonomi Islam dibangun (Ghofur 2017, 36).

Selanjutnya untuk merumuskan ekonomi syari'ah dalam konteks kekinian, Syamsul Anwar interpretasi syari'ah dengan membaginya ke dalam 3 (tiga) lapisan, yaitu: norma-norma dasar dan nilai-nilai filosofis (القيام الاساسية), asas-asas umum (الاصول الكامية), dan peraturan kongkrit (الاحكام التطبيقية). Nilai-nilai dasar bersifat abstrak dan universal serta sekaligus menggambarkan pokok-pokok fundamental ajaran Islam seperti tauhid, kemashlahatan, keadilan, persamaan, musyawarah dan lainnya. Asas-asas umum merupakan norma-norma tengah yang terletak antara dan sekaligus menjembatani nilai-nilai dasar dengan peraturan hukum kongkrit; atau kongkritisasi dari nilai dasar yang bersifat abstrak dan biasanya dirumuskan dalam asas-asas umum hukum Islam (النظاريات الفقهية) dan kaedah-kaedah hukum Islam (القواعد الفقهية). Sedangkan peraturan kongkrit merupakan kongkritisasi lebih lanjut dan merupakan penjabaran nilai-nilai di atasnya (Anwar 2002, 159, 2007, 15), sebagaimana terlihat dalam skema di bawah ini: 


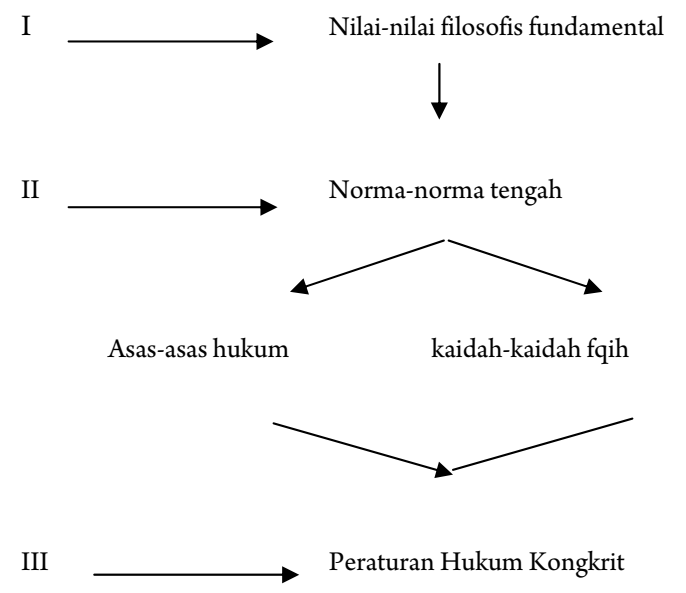

Dalam konteks pertingkatan itu, ekonomi Islam dibangun di atas dasar asumsi asumsi pada lapisan atas yang bersumber dari al-Qur'an dan hadiș, dimana penalaran rasional manusia menangkap asumsi level atas itu secara deduktif dan mengujinya dengan fakta empiris di kehidupan nyata secara induktif (Praja 2015, 65-67). Dengan kata lain prosedur untuk mendeduksi pernyataan-pernyataan ekonomi itu berasal dari aksioma-aksioma etik yang menghasilkan serangkaian hipotesis yang bisa diuji, sehingga fuqaha' ekonomi mampu membahas masalah baru dengan mengintegrasikan etika dan moral dan ekonomi ke dalam framework tunggal (Naqvi 2009, 67).

Islam menganjurkan adanya reformasi moral, sosial, ekonomi, dan institusional, untuk membantu merealisasikan tujuan-tujuan syari'ah (maqashid syari'ah) yaitu: keadilan dan kesejahteraan. Keadilan adalah esensi dari visi dan misi Islam. Implikasinya kezaliman di semua dimensi, termasuk ekonomi harus dihapus, misalnya: ketidakrataan, eksploitasi, monopoli, dan ketidakseimbangan hak dan kewajiban (F. Zein 2003, 197-98). Oleh karena itu perlu dinamisasi dalam memahami maqashid klasik karena obyek dan subyeknya hanya tertuju pada individu dan bersifat global saja. Ia juga kurang menfokuskan tujuan-tujuan spesifik dan topic-topik tertentu. Oleh karena itu, obyek dan subyek maqashid syari'ah saat ini bukan lagi individu saja tapi menjangkau dimensi yang lebih luas, seperti: masyarakat, bangsa, bahkan umat manusia. Perluasan jangkauan ini memberi kesempatan umat Islam untuk merespon 
tantangan-tangan global dan membantu merealisasikan maqashid menjadi rencana-rencana praksis untuk pembaharuan ekonomi umat manusia (Al-Khadimi 2010, 192).

\section{Kesimpulan}

Berdasarkan uraian di atas, dapat disimpulkan bahwa ekonomi Islam berkaitan erat dengan maqashid syari'ah yaitu hịz al-mal. Maqashid syari'ah adalah dasar bagi pengembangan ekonomi Islam karena bertujuan tujuan untuk menciptakan kesejahteraan dan kebahagiaan manusia dengan menyeimbangkan peredaran harta secara adil dan seimbang baik secara personal maupun sosial.

Pemahaman terhadap maqashid syari'ah merupakan sebuah keharusan dalam berijtihad untuk menjawab berbagai problematika ekonomi. Pemahaman terhadap maqashid syari'ah tidak saja diperlukan untuk merumuskan kebijakan-kebijakan yang bersifat makro ekonomi, tetapi juga kebijakan yang bersifat mikro ekonomi.

Dalam konteks ekonomi, maqashid syari'ah memiliki peran ganda, yaitu: sebagai alat kontrol sekaligus alat perekayasa sosial untuk mewujudkan kemashlahatan manusia. Ia memberikan landasan filosofis yang rasional dari aktivitas ekonomi. Tanpa maqashid syari'ah, pemahaman dan praktik ekonomi Islam akan menjadi sempit, kaku, statis, dan lambat. Ekonomi Islam akan kehilangan spirit dan substansi syari'ahnya. Tetapi sebaliknya, dengan maqashid syari'ah ekonomi Islam berkembang elastis, dinamis, sesuai dengan karakter syari'ah Islam yang bersifat universal dan relevan untuk segala ruang dan waktu (صالح لكل زمان و مكان). 


\section{DAFTAR PUSTAKA}

'Amiri, Abdallah M. Al Husain Al. 2004. At Thufi's Refutation of Traditional Muslim Juristic Sources of Law and His View on the Priority If Regard for Human Welfare as the Highest Legal Sources or Principle. Jakarta: Gaya Media Pratama.

'Audah, Jaser. 2013. Al-Maqashid Untuk Pemula. Yogyakarta: UIN Sunan Kalijaga Yogyakarta Press.

__— 2015. Membumikan Hukum Islam Melalui Maqashid Syari'ah. Bandung: Mizan.

Abdullah, Boedi. 2010. Peradaban Pemikiran Ekonomi Islam. Bandung: Pustaka Setia.

Abdullah, M. Amin. 2004. Neo Ushul Figh Menuju Ijtihad Kontemporer;

Paradigma Alternatif Pengembangan Ushul Fiqh Dan Dampaknya

Pada Fiqh Kontemporer. ed. Riyanta. Yogyakarta: Fakultas Syariah UIN SuKa.

_—_. 2007. Islamic Studies Dalam Paradigma Integrasi-Interkoneksi. Yogyakarta: SUKA Press.

___. 2012. Islamic Studies Di Perguruan Tinggi: Pendekatan Integratif Interkonesktif. Yogyakarta: Pustaka Pelajar.

—_—. 2015. Studi Agama: Normativitas Dan Historisitas,. Yogyakarta: Pustaka Pelajar.

Al-Fasi, 'Allal. 1963. Maqashid As-Syari'ah Al-Islamiyyah Wa Makarimuha.

Maktabah al-Wahdah al-Arabiyyah ad-Dar al-Baiḍa.'

Al-Kaaf, Abdullah Zaky. 2002. Ekonomi Dalam Perspektif Islam. Bandung: Pustaka Setia.

Al-Khadimi, Nuruddin Mukhtar. 2010. Fushul Fi Al-Ijtihad Wa AlMaqashid. Tunis: Dar as-Salam.

Al-Maudūdi, Abul A'lā, and terj. Imām Munawwir. 2005. Asas Ekonomi Islām Al-Maudūdi. Surabaya: Bina Ilmu.

Al-Qarḍawi, Yusuf. 2006. Fiqh Maqashid Syari'ah. Jakarta: Pustaka AlKautsar. 
Anwar, Syamsul. 2002. "Pengembangan Metode Penelitian Hukum Islam"

Dalam Madzhan Jogja Menggagas Paradigma Ushul Fiqh Kontemporer. Yogyakarta: Ar Ruzz Press.

___ 2007. Hukum Perjanjian Syariah: Studi Tentang Teori Akad Dalam Fiqih Muamalat. Jakarta: Raja Grafindo Persada.

Ar-Raisuni. 2003. Nażariyyat Al-Maqashid 'Inda Al-Imam as-Syatibi. Rabat al-Magrib: Dar al-Aman.

As-Syayihi, Ahmad Abdurrahim. 1993. Risalah Fi Ri'ayat Al-Mashlahah

Li Imam at-Tufi. Cairo: Dar al masriyah al lubnaniyah.

Asy'arie, Musa. 2015. Filsafat Ekonomi Islam. Yogyakarta: LESFI.

Aziz, Abdul. 2013. Etika Bisnis Perspektif Islam: Implementasi Etika Islami Untuk Dunia Usaha. Bandung: Alfabeta.

Chamid, Nur. 2010. Jejak Langkah Sejarah Pemikiran Ekonomi Islam. Yogyakarta: Pustaka Pelajar.

Chapra, M Umer. 2000. Islam Dan Tantangan Ekonomi. Jakarta: Tazkia Institute.

Damsar. 2015. Pengantar Teori Sosiologis. Jakarta: Kencana Prenada Media.

Ghofur, Abdul. 2017. Pengantar Ekonomi Islam. Jakarta: Raja Grafindo Persada.

Hakim, Atang Abdul. 2011. Fiqih Perbankan Syariah: Transformasi Fiqih Muamalah Ke Dalam Peraturan Perundang-Undangan. Bandung: Refika Aditama.

Haq, Hamka. 2007. As-Syațibi; Aspek Teologis Mashlaḥah Dalam Kitab Muwafaqat. Surabaya: Erlangga.

Harahap, Sofyan S. 2011. Etika Bisnis Dalam Perspektif Islām. Jakarta: Salemba Empat.

Ḥusain, Ahmad al Mursi. 2013. Maqashid Syari'ah. Jakarta: Amzah.

Karim, Adiwarman. 2011. Bank Islam: Analisis Fiqih Dan Keuangan. Jakarta: PT. Raja Grafindo Persada.

Koto, Alaiddin. 2014. Filsafat Hukum Islam. Jakarta: Rajawali Press. 
Mardani. 2015. Fiqh Ekonomi Syariah: Fiqh Muamalah. Jakarta: Prenada Media Group.

Miles, Mathew B., and A. Michael Huberman. 2009. Analisis Data Kualitatif (Qualitatif Data Analysis). Jakarta: UI Press.

Mu'allim, Amir dkk. 2008. Menjawab Keraguan Ekonomi Syari'ah. Yogyakarta: Shafiria Insani.

Mufid, Mohammad. 2016. Ushul Fiqh Ekonomi Dan Keuangan Kontemporer Dari Teori Ke Aplikasi. Jakarta: Kencana Prenada Media.

Muhammad. 2009. Ekonomi Islam: Kontribusi Fundamentalisme Islam Untuk Ekonomi Islam Dan Perdebatan Tentang Fundamentalisme, Kapitalisme Dan Revivalisme Islam Menuju Dekonstruksi Ekonomi Berbasis Nilai. Malang: Empat Dua.

Muhtada, Dani. 2003. "Melacak Dimensi Ontologis Ekonomi Islam." Jurnal Ilmiah Refleksi VI(2).

Muslehuddin, Muhammad. 1997. Filsafat Hukum Islam Dan Pemikiran Orientalis: Studi Perbandingan Hukum Islam. Yogyakarta: Tiara Wacana.

Naqvi, Syed Nawab Haider. 2009. Menggagas Ekonomi Islam. Yogyakarta: Pustaka Pelajar.

Obaidullah, Muhammad. 2001. "Ethics and Efficiency in Islamic Stock Markets, International Journal of Islamic Financial Services." International Journal of Islamic Financial Services 3(2).

Praja, Juhaya S. 2015. Ekonomi Syariah. Bandung: Pustaka Setia.

Rahman, Fazlur. 1984. Islam and Modernity: Transformation of an Intellectual Tradition. ed. Ahsin Muhammad. Bandung: Pustaka.

Ridwan, Muhtadi. 2011. Al-Qur'an Dan Sistem Perekonomian. Malang: UIN Maliki Press.

Shaleh, Adbdul Mun'im. 2012. Otoritas Mashlahah Dalam, Mażhab Syafi'i. Yogyakarta: Magnum Pustaka.

Shaleh, Ahmad Munif. 2002. Filsafat Hukum Islam Al-Gazali: Mashlah ah Mursalah Dan Relevansinya Dengan Pembaharuan Hukum Islam. Jakarta: Pustaka Firdaus. 
Supriyadi, Dedi. 2014. Ushul Fiqh Perbandingan. Bandung: Pustaka Setia.

Thahir, A. Halil. 2015. Ijtihad Maqasidi, Rekonstruksi Hukum Islam Berbasis Interkoneksitas Maslahah. Yogyakarta: LKiS.

UII, P3EI. 2008. Ekonomi Islam. Jakarta: Rajawali Press.

Yasid, Abu. 2007. Nalar Dan Wahyu Interrelasi Dalam Proses Pembentukan Syari'at. Jakarta: Erlangga.

Zahrah, Muhammad Abu. 2009. Tarikh Al-Mazahib Al-Islamiyah Fi asSiyasah Wa Al-'Aqa'Id Wa at-Tarikh Al-Mazahib Al-Fiqhiyyah. Kairo: Dar al-Fikri.

Zein, Fuad. 2003. Neo Ushul Fiqh Menuju Ijtihad Kontemporer; Aplikasi Ushul Fiqh Dalam Mengkaji Keuangan Kontemporer. ed. Riyanta. Yogyakarta: Fakultas Syariah UIN SuKa Press.

Zein, Satria Effendi M. 2009. Ushul Fiqh. Jakarta: Kencana. 